\title{
A Comparative Study of Two Pressure RELIEVING TECHNIQUES ON THREE DIFFERENT WHEELCHAIR CUSHIONS
}

\begin{abstract}
Introduction: Pressure relief done by a spinal cord injured patient is of utmost importance in order to prevent pressure sore formation. Some pressure-relieving techniques are described in previous literature, but their effectivity has not yet been determined on different wheelchair cushions.

Null Hypothesis (HO): The null hypothesis (HO) stated for this study is that there is no difference in the effectivity of forward leaning and forward leaning towards the left as pressure relieving techniques for quadriplegic wheelchair users over the different wheelchair cushions.
\end{abstract}

Design: An analytical experimental study design using a conve-

\section{Eksteen C, BScPhysio, MEd, PhD ${ }^{1}$, Cilliers P, B.Eng(Hons), M.S.(EE), PhD², Swanepoel A, BSc(Hons) MSC ${ }^{3}$, Vermaak $E^{4}$, Trollip $\mathbf{Q}^{4}$, Wilford T4, Van Dyk PM ${ }^{4}$}

1 Department of Physiotherapy, University of Pretoria.

2 Hermanus Magnetic Observatory.

3 Department of Statistics, University of Pretoria.

4 Research Assistant, Department of Physiotherapy, University of Pretoria. nient sample group of ten complete lesion quadriplegics (C6 to T1) was performed at the Physiotherapy Department, University of Pretoria.

Method: Interface pressure (in $\mathrm{mmHg}$ ) over the ischial tuberosities and upper thigh areas was measured using the Talley Oxford Pressure Monitor MKII with a 12-way matrix cell system.

Results and Conclusion: The Friedman test for associated observations indicated statistically that the leaning diagonally forward pressure relieving technique is more effective for all three wheelchair cushions used in this study.

KEYWORDS: PRESSURE RELIEVING TECHNIQUE, PRESSURE SORE, QUADRIPLEGIC, INTERFACE PRESSURE, WHEELCHAIR CUSHION.

\section{INTRODUCTION}

The annual prevalence of spinal cord injuries (SCI) in the United States of America is 200000 to 250000 and 24 to 50 persons per million people. The treatment and rehabilitation needs of these patients are a socio-economic challenge to society (Muslumanoglu et al, 1997).

During the last decade the life expectancy has greatly improved for wheelchair bound patients with SCI. Nevertheless $50 \%$ of all patients with quadriplegia and $30 \%$ of patients with paraplegia are hospitalized during their lifetime because of pressure related problems (Rosenthal et al 1996).

The development of pressure sores is one of the most common causes of delay in effective rapid rehabilitation of the acute spinal cord injury (SCI) patient. A patient who has had a pressure sore once will remain at risk of developing a pressure sore in the future (Bogie et al 1992).

Although there are multiple factors contributing to the formation of pressure ulcers, many authors agree that the cause of a pressure ulcer is mainly attributed to inactivity and prolonged pressure (Garber et al 1978; Levine et al 1989; Exton-Smith and Sherwin 1961) over an area of soft tissue covering a bony prominence such as the ischial tuberosities, greater trochanters, sacrum and heels (Kernozek and Lewin, 1998; Phillips et al 1987). More pressure sore occurrences are attributed to the sitting position than to the supine or other positions (Zacharow, 1984).

Body tissues can generally tolerate high pressure for short periods, but blood supply and lymph drainage are impaired if such pressure is prolonged. This results in tissue hypoxia, trauma and possible necrosis. Kosiak (1961), Reswick and Rogers (1976) and Patterson and Fisher (1980) suggested that capillary pressure might very well be the threshold pressure for inducing tissue damage under the bony prominences. Therefore in order to prevent the formation of pressure sores, the interface pressure between the patient and the supporting surface must be kept below the pressure required to cause capillary closure. The latest research on the effect of prolonged pressure on the skin indicated that pressure of $45 \mathrm{~mm}$ $\mathrm{Hg}$ is needed to result in the closure of the capillary circulation with necrosis of the skin and the formation of a pressure sore (Salcido et al 1993). Due to the nature of the lesion, SCI patients lack sensory feedback on discomfort due to pressure build-up which results in the need for active pressure relief in the area over their ischial tuberosities. The result is that in sitting pressure often increases for a prolonged time above the level of capillary closure over the ischial tuberosities, because of prolonged pressure over these areas (Henderson et al 1994; Park, 1992).

\section{CORRESPONDENCE TO:}

Carina Eksteen

Department of Physiotherapy

P O Box 667

Pretoria 0001

Tel: (012) 354-1249 (w)

Email: carina.eksteen@up.ac.za 
The Wheelchair cushion plays a vital role in the prevention of pressure sores as one of the many devices able to reduce interface pressure between the patient and the supporting surface. Commercially available wheelchair cushions have certain functional characteristics that influence the interface pressure and the patient's subsequent tissue response. It is thus reasonable to expect that the various types of cushions will have different pressure relief properties and therefore different reactions to pressure relief techniques can be expected. Previous studies have revealed that no single cushion is clearly ideal for all patients and therefore the selection and fitting of cushions to patients should be done on an individual basis (Somiya et al 1996). It becomes essential to not only prescribe a specific cushion to a specific patient, but also to educate the patient in the most effective pressure relief technique that should be used with the cushion.

Bromley (1998) describes two techniques that can be performed independently by quadriplegics with lesions at levels of the sixth cervical vertebra and below. These techniques are forward leaning and leaning diagonally forward. No literature regarding the different types and effectiveness of pressure relieving techniques could be obtained. There appears to be a distinct lack of research in this field.

The null hypothesis (H0) stated for this study is that there is no difference in the effectivity of forward leaning and forward leaning towards the left as pressure relieving techniques for quadriplegic wheelchair users over the different wheelchair cushions.

Alternative hypothesis (H1): there is a difference in the effecitivity of forward leaning and diagonally forward leaning towards the left as pressure relieving technique for quadriplegic wheelchair users over the different wheelchair cushions.

This is relevant to physiotherapists since they are directly involved in the teaching of pressure relief techniques, providing advice on the prevention of pressure sores and the purchasing of the most suitable wheelchair cushion which forms an integral part of the rehabilitation of SCI patients.

\section{Aim}

To determine the effect of two different pressure relieving techniques on three different wheelchair cushions.

The objectives of this study were therefore to:

- Determine the interface pressure during normal sitting on three different wheelchair cushions.

- Compare the interface pressure during two pressure relieving techniques (forward leaning and leaning diagonally forward) described in sitting.

- Determine the most effective pressure relieving technique for the three cushions.

\section{METHOD \\ Ethical Considerations}

This study was approved by the Ethics Committee of the Faculty of Health Sciences, University of Pretoria and Pretoria Academic Hospital, approval number S36/2000.

\section{Research method}

An analytical experimental study design was used on a convenient sample group.

\section{Sample group (Inclusion and Exclusion Criteria)}

The Gauteng branch of the Quadriplegic Association of South Africa (QASA) was contacted to get the names of people who would meet the inclusion and exclusion criteria and who would be willing to participate in the study. The inclusion criteria entailed that participants had to have a complete spinal cord lesion of the cervical spine, living independently, had to be able to perform pressure relieving techniques required in this study and had to give voluntary informed consent. Exclusion criteria entailed that they could not participate in the study if they had a pressure sore or had any underlying medical condition.

\section{Apparatus}

\section{a) Wheelchair}

A standard wheelchair with removable armrests has been used throughout the study. The armrests had been removed for the duration of the experiment. A flat piece of melamine board was placed on the seating surface of the wheelchair to provide a flat surface for the cushions and was kept in place for the duration of the experiment.

\section{b) Cushions}

The following cushions were used for all patients:

\section{Polyurethane Foam Cushion}

The Polyurethane foam cushions have a cut away area underneath the patient's sacrum and ischial tuberosities. In this study three different cushions with cut-away areas, $130 \mathrm{~mm}$ (small), $150 \mathrm{~mm}$ (medium) or $170 \mathrm{~mm}$ (large) were used. The distance between the patient's ischial tuberosities was measured to determine which of the three cushions would be most suitable for him.

\section{Dry Flotation Air Cushion}

The commercially manufactured dry flotation air cushion is a system of soft flexible and interconnected air cells. These cells were inflated according to the instruction booklet received with each cushion. The objective of the adjustment procedure is to "immerse" the user as deeply as possible in the cushion without it bottoming out.

\section{Silicon Gel Cushion}

The silicone gel cushion is also a commercially manufactured standard cushion. Therefore this cushion has no variables that could affect the outcome of the measurements performed on it.

\section{c) Interface Pressure Monitor}

The TALLEY Oxford Pressure Monitor $M K$ II (OPM MKII) was used for measuring the interface pressure. The machine was calibrated before every data collection session. The Talley (OPM MKII) has a 12-Way Matrix cell system that is a configuration of three rows of four cells each (Figure 1), positioned equidistant from each other and covering an area of $9000 \mathrm{~mm}^{2}$ in total. The matrix is manufactured out of transparent light plastic material.

\section{Data Collection Procedure}

The process and the aims of the study were explained to the subjects, as well as the risks and benefits thereof. The identity of subjects and personal research results are held strictly confidential.

Subjects were dressed with underwear that maintained their dignity, while still allowing accurate measurements to be taken. Thereafter the subjects were weighed on a calibrated sitting mass scale.

The patient was then put into a fourpoint kneeling position with the trunk 
Figure 1: Placing of the matrices.

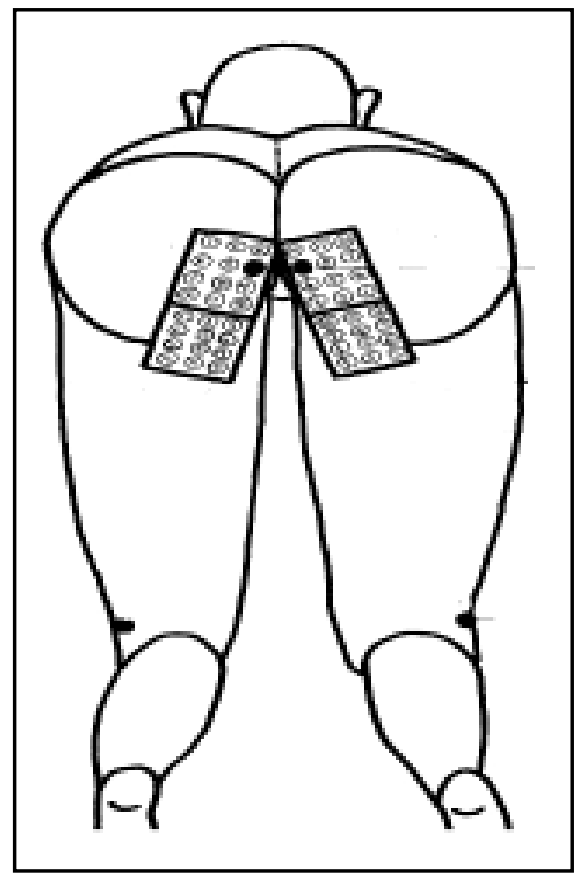

supported over a low a bench. In this position, which resembles the position of the trunk, hips and the leg in sitting, the ischial tuberosities were palpated and marked with a skin pencil and the distance between the ischial tuberosities measured in millimetres. This measurement was taken to determine the size of the polyurethane foam cushion required for that subject. The matrices were placed over the ischial tuberosities and upper thigh regions and were kept the same for each patient. The matrices were placed in such a way that the leads attached to the Oxford Pressure Monitor MK II (OPM MKII) faced from medial to lateral in order to prevent overlapping between leads and cells. The matrixes were then attached to the buttocks with Leukotape P (by Beiershof).

The first measurement of the interface pressure between the patient and the cushion, which served as the baseline measurement, was taken with the patient in normal sitting position. The second and third measurements were taken during the two pressure relief techniques respectively

Pressure relief technique 1: Forward leaning (PRT1)

Pressure relief technique 2: Leaning forward diagonally to the left (PRT2)

The pressure in all 48 cells (4 matrices x 12 cells each) was measured in $\mathrm{mm} \mathrm{Hg}$ and stored by the OPM MKII. This data was then transferred to a computer at a later stage. Each pressure relief position was held for 15 seconds and the average pressure per cell during this time interval was recorded, as prescribed in the OPM MKII manual.

All readings were taken in the same chronological sequence by the same researcher on every occasion to eliminate inconsistency in interrater reading of measurements. Intrarater reliability was ensured by constant monitoring of the each others actions during the performance of the experiment. Once the last measurement was completed the subjects were cleaned, dressed, transferred back to their own wheelchairs and thanked for their participation.

\section{Data Analysis}

The Friedman analysis of variance was used to compare the results of the participants $(n=10)$ on the three cushions, as well as the average pressure measurements obtained on the three cushions. The T-test could not be used because the sample group $(n=10)$ was less than 30 and there were no evidence that the population was normally distributed. The tests were conducted at the 5\% level of significance.

a) The average (mean), minimum (min), and maximum (max) values of the 6 cells under the left (L) (matrix 1) and right (R) (matrix 3) ischial tuberosities (IT.) were calculated in neutral sitting, forward leaning (PRT1), and leaning diagonally forward to the left (PRT2) for all 10 subjects. The difference between the average (mean) values for these six cells in matrices 1 and 3 respectively during PRT1 and PRT2 were calculated and compared with those in normal sitting. The number of statistically significant values according to the Wilcoxon test (which was used to compare the results under the left IT and UT with the results under the (R) IT and UT) was also calculated for those 6 cells per area. This procedure was repeated on each cushion.

b) Exactly the same procedure as in a) was followed except on this occasion values were calculated for the 6 cells underlying the $\mathrm{L}$ and $\mathrm{R}$ upper thighs, in the specific area where the thigh crosses the edge of each cushion (cells 7-12 of matrix 2 and cells 1-6 of matrix 4 respectively).

c) The average (mean), minimum and maximum values for each matrix were calculated over all 12 cells on each matrix per cushion during neutral sitting, PRT1 and PRT2.

\section{RESULTS}

Ten quadriplegic patients with complete lesions were willing to participate in this study, three of whom have SCI at C6 level, three with SCI at C7 level, three with SCI at C8 level and one at T1 level. All the subjects were male, and ages ranged from 23 to 35 years. Their time of independent living in a wheelchair ranged from 4 weeks to 15 years. All ten subjects complied to the other inclusion and exclusion criteria.

In the neutral sitting position the (L) IT region (cells 1-6 matrix 1) had a mean pressure slightly below capillary closure pressure (CCP) of $45 \mathrm{mmHg}$. The mean pressure under the $(\mathrm{R})$ IT region (cells 7-12 matrix 3) was $7 \mathrm{mmHg}$ above CCP (Table 1, Figure 1, Figure 4). The interface pressure under the UT regions (cells 7-12 of matrix 2 and cells 1-6 of matrix 4) also indicate higher pressure under the (R) UT region than the left. From these readings the conclusion can be made that the patients sat with unequal weight bearing, specifically more on the (R) than the (L) The unequal weight bearing in normal sitting is displayed in Figures $4 \& 5$. The average pressure under the (L) IT region was less than ICC, which means that under these conditions the patient did not need pressure relief under the (L) IT region (Figure 2). The average pressures under the (R) IT and both UT regions were more than $\mathrm{CCP}$ in neutral sitting.

During PRT1 the pressure under the (L) and (R) IT regions decreased by approximately 6 and $4 \mathrm{mmHg}$ respectively. Although the average pressure under the (R) IT decreased during leaning forward (PRT1) the value specifically under the (R) IT did not reach a point lower than CCP. During PRT1 there appeared to be no real change under the (L) UT region (Matrix 2, cells 7-12. This was expected because the patients were already weight bearing more on the left thigh than the right thigh). However an increase of nearly $20 \mathrm{mmHg}$ occurred under cells 
1-6 of Matrix 4 under the (R) UT region. The apparent explanation for this is that the patient was leaning more to the right side while leaning forward, probably due to the fact that he/she was sitting off balance (more to the left side) before he/she performed PRT1 and during PRT1 over-corrected the weight shift to the right side. On Figure 5 the threedimensional changes in pressure during PRT1 is graphically displayed.

During PRT2 (diagonally leaning to the left) a pressure relief value of $19 \mathrm{mmHg}$ was seen under the (R) IT area. The average value under the (R) IT region decreased to lower than $\mathrm{CCP}$ (Table 1, Figure 2 and Figure 6).

Thus, for the foam cushion, the PRT2 technique can be regarded as the better technique for relieving pressure under the IT regions.

\section{SILICON GEL CUSHION}

From Figure 2 and Figure 6 it appears that the patients were sitting with equal weight bearing between the $(\mathrm{L})$ and $(\mathrm{R})$ IT regions as well as under the (L) and (R) UT regions (Figure 3, Figure 7) in neutral sitting. However the interface pressure under the IT regions was respectively 17 and almost $20 \mathrm{mmHg}$ higher than $\mathrm{CCP}(45 \mathrm{mmHg})$, causing a
Table 1: A comparison of the mean of the six cells in matrices 1 and 3 that are situated over the ischial tuberosities (measured in $\mathbf{~ m m ~} \mathbf{~ H g}$ ).

\begin{tabular}{|l|c|c|c|c|}
\hline CUSHION & SIDE & NEUTRAL & PRT1 & PRT2 \\
\cline { 3 - 5 } & MATRIX & Mean & Diff $* *$ & Diff** \\
\hline FOAM & L (1) & 42.1 & 5.8 & 0.8 \\
& R (3) & 52.5 & 3.6 & 18.8 \\
\hline Silicon gel & L (1) & 61.9 & 16.8 & -9.0 \\
& R (3) & 64.2 & 18.1 & 2.7 \\
\hline Dry floatation & L (1) & 42.5 & 13.2 & -11.4 \\
air & R (3) & 43.9 & 12.8 & -5.1 \\
\hline
\end{tabular}

- **: The difference between the mean value of all six cells in the specific position and in neutral sitting.

- A negative value denotes an increase in pressure.

- A positive value denotes a decrease in pressure.

Table 2: A comparison of the mean of the six cells in matrices 2 and 4 that are situated over the upper thigh area (measured in $\mathbf{~ m m ~} \mathbf{~ H g}$ ).

\begin{tabular}{|l|c|c|c|c|}
\hline \multirow{2}{*}{ CUSHION } & SIDE & NEUTRAL & PRT1 & PRT2 \\
\cline { 3 - 5 } & MATRIX & Mean & Diff $* *$ & Diff** \\
\hline FOAM & L (2) & 57.0 & 0.2 & -15.4 \\
& R (4) & 50.1 & -19.4 & 16.2 \\
\hline Silicon gel & L (2) & 36.4 & -24.1 & -22.2 \\
& R (4) & 35.8 & -6.4 & 15.2 \\
\hline Dry floatation & L (2) & 33.5 & -5.2 & -12.8 \\
air & R (4) & 36.4 & -4.6 & 14.6 \\
\hline
\end{tabular}

- **: The difference between the mean value of all six cells in the specific position and in neutral sitting.

- A negative value denotes an increase in pressure.

- A positive value denotes a decrease in pressure.

Figure 2: The six cells in matrices 1 and 3 that are situated over the ishial tuberosities on all 3 cushions in neutral sitting, PRT1 an PRT2.

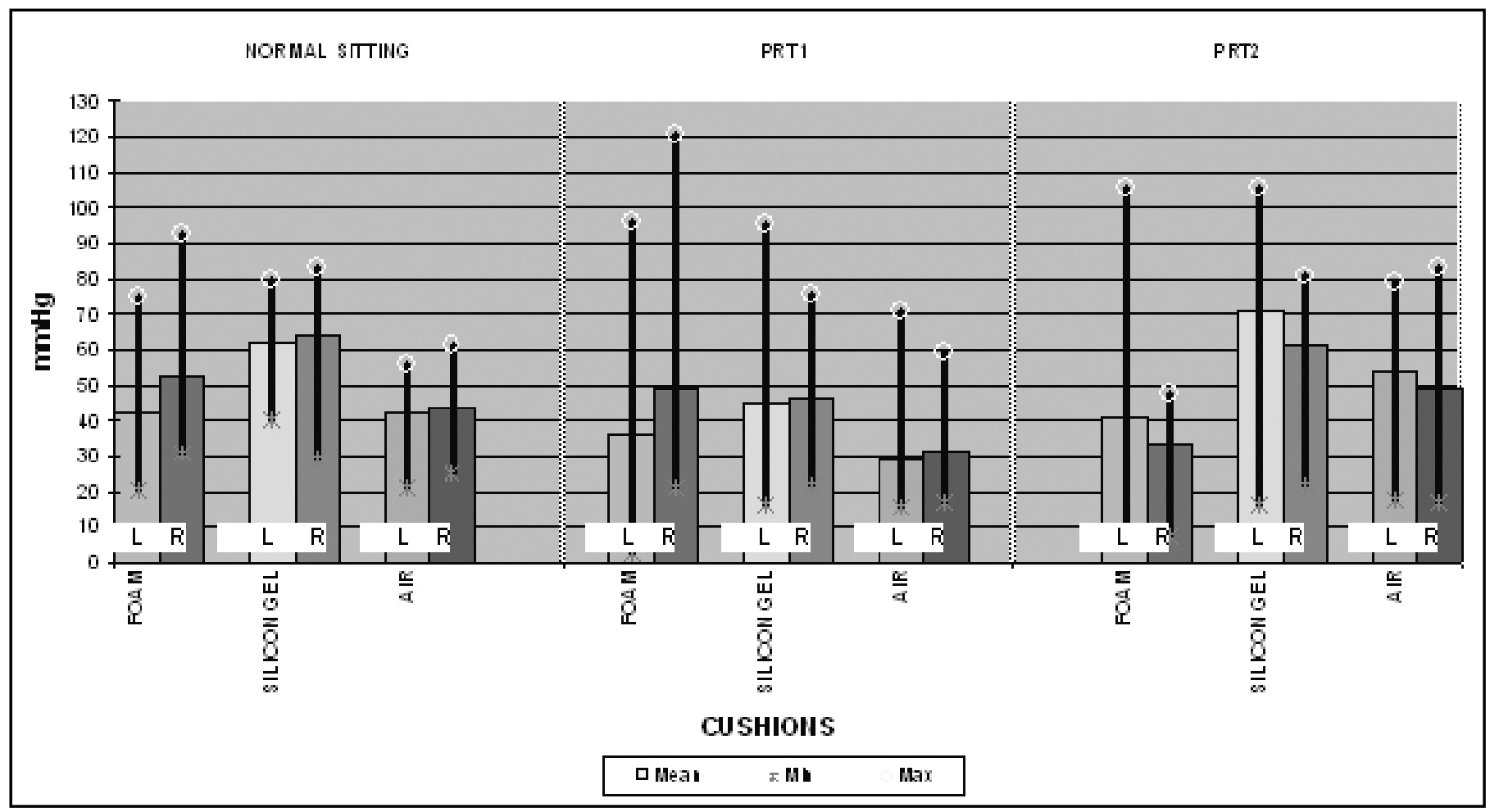


high risk for development of pressure sores under the IT regions. The average interface pressure under the UT regions almost equaled CCP.

During PRT1 interface pressure values under the (L) and (R) IT regions decreased to approximately $45 \mathrm{mmHg}$ under the IT regions and increased under the UT regions as expected (Figure 3 ). However although the patients were instructed to lean forward, it seems from the measurements that they leaned forward more towards the left than the right (Figure 3, Figure 8). The clinical significance of the pressure relief under the IT region is that during PRT1 the interface pressure reached the value of $45 \mathrm{mmHg}$, which is the point of CCP.

During PRT2 the interface pressure under the $(\mathrm{R})$ IT region decreased with $2.7 \mathrm{mmHg}$ (Table 1, Figure 9) Under the (R) UT region the interface pressure decreased with $15.2 \mathrm{mmHg}$ (Table 2, Figure 3, Figure 9).

The average pressure in all the cells of matrix 3 ((R) IT region) showed a statistically meaningful decrease of approximately $30 \mathrm{mmHg}$ for PRT2 (Table 3) compared with a decrease of approximately $20 \mathrm{mmHg}$ for PRT1.
PRT2 seems therefore the best pressure relieving technique under the UT regions for the silicon gel cushion.

\section{DRY FLOTATION AIR CUSHION}

On the dry flotation air cushion the patients were in equal weight bearing between the $(\mathrm{L})$ and $(\mathrm{R})$ IT regions in neutral sitting. Both $(\mathrm{L})$ and $(\mathrm{R})$ pressure values under the IT regions in neutral sitting were just below CCP (Figure 2). Both (L) and (R) interface pressure values under the UT were below CCP in neutral sitting.

Table 3: A comparison of the mean of all twelve cells in matrices $1,2,3$ and 4 (measured in $\mathrm{mm} \mathrm{Hg}$ ).

\begin{tabular}{|c|c|c|c|c|}
\hline \multirow[t]{2}{*}{ CUSHION } & \multirow{2}{*}{$\begin{array}{c}\text { SIDE } \\
\text { MATRIX }\end{array}$} & NEUTRAL & PRT1 & PRT2 \\
\hline & & Mean & Diff ** & Diff** \\
\hline \multirow[t]{4}{*}{ FOAM } & 1 (L) & 46.8 & 6.5 & -5.4 \\
\hline & 2 (L) & 63.5 & 2.8 & -15.6 \\
\hline & 3 (R) & 54.2 & 9.6 & 7.0 \\
\hline & $4(R)$ & 55.8 & -11.7 & 18.5 \\
\hline \multirow[t]{4}{*}{ Silicon gel } & 1 (L) & 58.4 & 13.7 & -21.1 \\
\hline & 2 (L) & 44.6 & -16.8 & -24.2 \\
\hline & 3 (R) & 59.5 & 19.6 & 30.2 \\
\hline & $4(R)$ & 40.0 & -5.3 & 14.2 \\
\hline \multirow[t]{4}{*}{ Dry floatation } & 1 (L) & 41.7 & 12.1 & -12.2 \\
\hline & 2 (L) & 39.1 & -5.4 & -18.5 \\
\hline & $3(R)$ & 38.9 & 5.7 & 9.8 \\
\hline & $4(R)$ & 38.4 & -4.0 & 13.7 \\
\hline
\end{tabular}

- **: The difference between the mean value of all six cells in the specific position and in neutral sitting.

- A negative value denotes an increase in pressure.

- A positive value denotes a decrease in pressure.

Figure 3: The six cells in matrices 2 and 4 that were situated over the uppr thigh regions on all 3 cushions in neutral sitting, PRTI an PRT2.

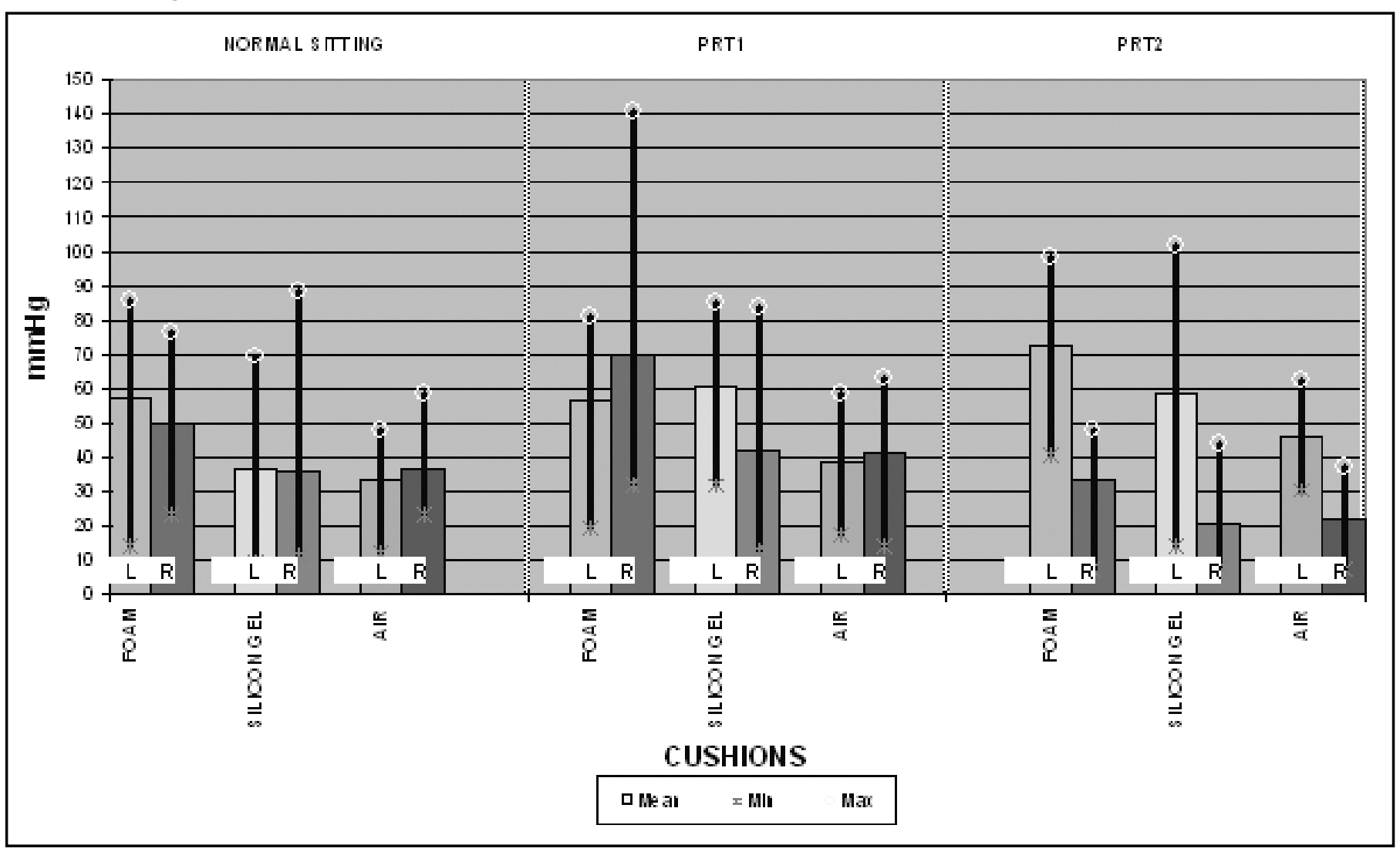


The pressure relief under the IT regions during PRT1 was approximately $13 \mathrm{mmHg}$ for both IT regions (Table 1, Figure 2 and Figure 11). During PRT2 the pressure increased to above CCP for both IT regions, the $(\mathrm{R})$ IT region (the area which was supposed be have more pressure relief) displaying a pressure of approximately $49 \mathrm{mmHg}$ (Table 1, Figure 2). However, greater pressure relief can be observed in the changes during PRT2 under the (R) UT region (Table 2, Figure 3 and Figure 12) of approximately $15 \mathrm{mmHg}$.

\section{CONCLUSION}

The difference between the pressure relief that took place under the (L) IT (matrix 1) region during PRT1 (forward leaning) on the foam, silicon and air cushions was not statistically significant $(p=0.670)$. Clinical significance is however determined by the cushion on which the lowest interface pressure under CCP (45 $\mathrm{mmHg}$ ) is observed. In this case it was the air cushion.

The pressure relief under the $(\mathrm{R})$ IT region during PRT1 was statistically better on the silicon gel cushion than on the foam and the air cushions ( $\mathrm{p}=0.045)$. Clinically the lowest interface pressure that was observed under the (R) IT and UT regions on the silicon cushion, was still higher than the interface pressure that was observed under the same areas on the air cushion. Clinically the lowest value under CCP for the IT regions was achieved on the air cushion.

During PRT2 the difference in interface pressure between neutral sitting and PRT2 for the (R) IT region was again statistically significant $(p=0.001)$ on the silicon cushion. Clinically however the lowest mean interface pressure was observed on the air cushion, which is well below CCP (Table 3, Figure 12).

The conclusion can therefore be reached that although the difference in interface pressure under the IT regions in neutral sitting and PRT2 is statistically significant on the silicon cushion, the pressure relief under the same area during PRT2 on the air cushion as well as the foam cushion, is clinically significant because of the low mean value of interface pressure under the $(\mathrm{R})$ IT region was in both cushions well below CCP.

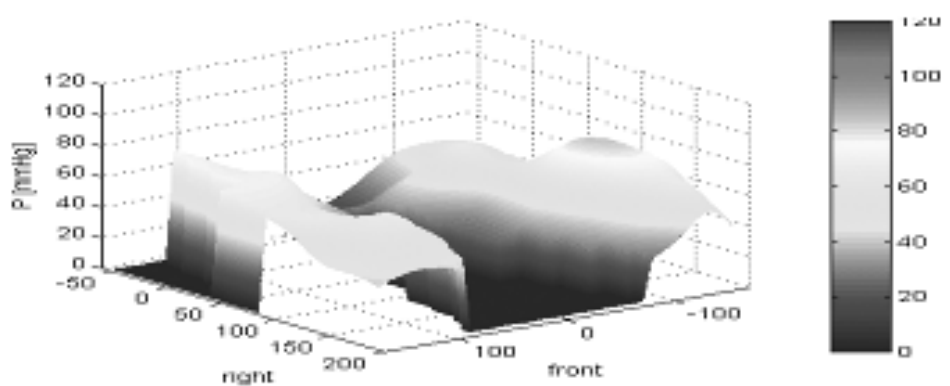

Figure 5: Foam: Forward leaning (PRT1).

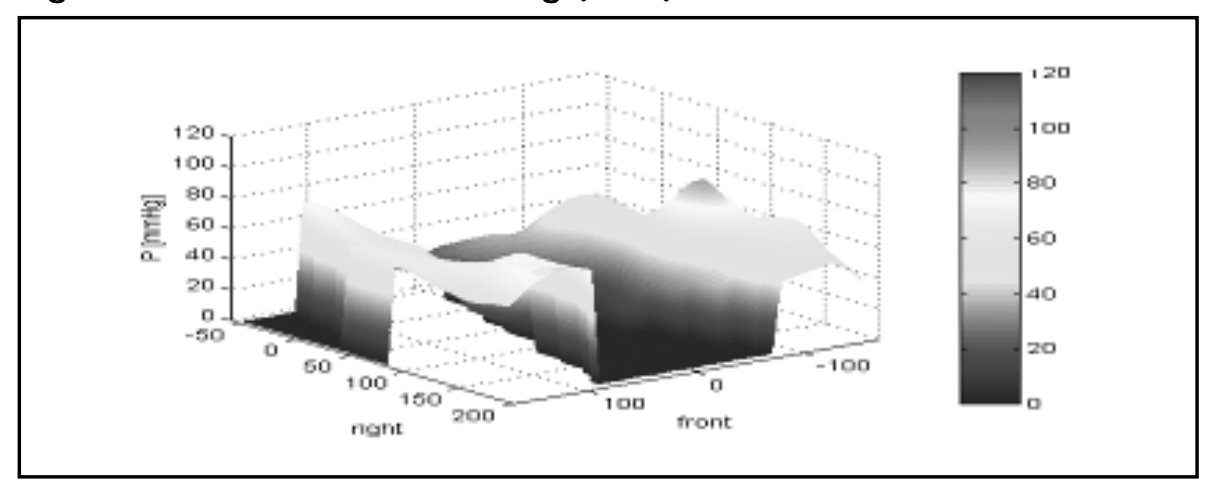

Figure 6: Foam: Diagonally forward leaning (PRT2).

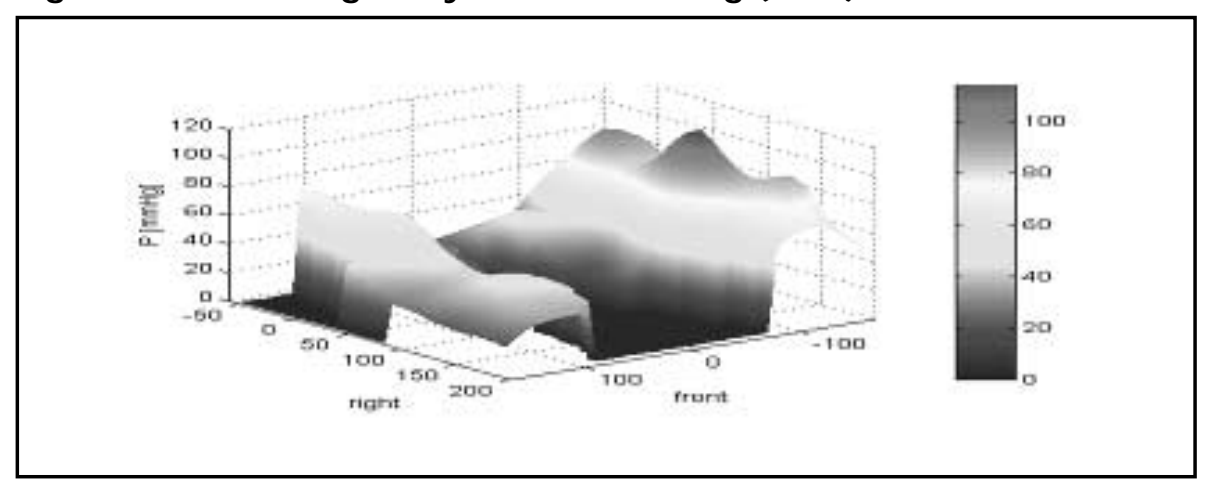

Figure 7: Silicon Gel cushion: Neutral sitting.

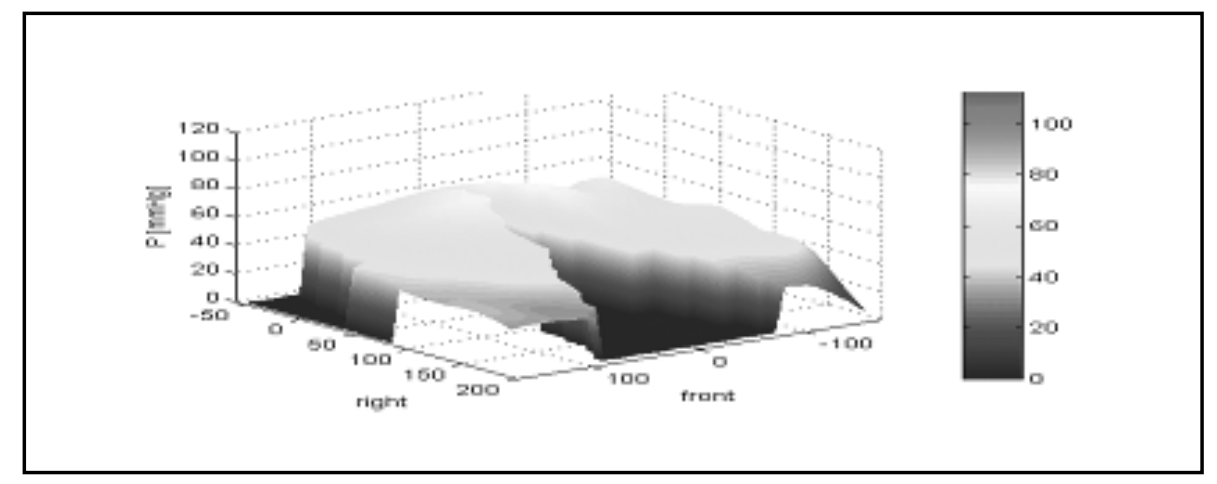

\section{LIMITATIONS AND RECOMMENDATIONS}

Symmetrical positioning and equal weight distribution of the subject on each cushion before pressure relieving techniques are tested is a priority. Visual observation of symmetrical sitting is not adequate. The statistical software used in this study could not give a visual graphic representation of the patient's weight distribution in neutral sitting before the experiment started. Measuring the interface pressure under the sacrum is a further aspect that should be considered a priority. The findings of this study could also be compared to PRT1 and PRT2 with the patient seated on his own cushion and wheelchair. Further research should examine more subjects and also different ways of independent pressure relieving techniques. 


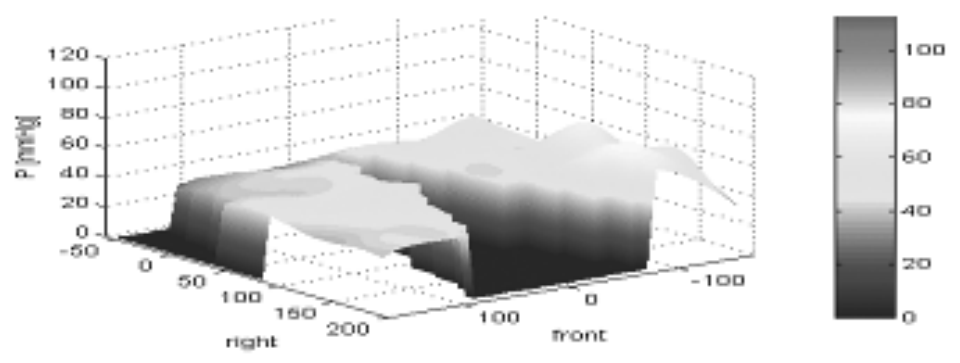

Figure 9: Silicon Gel cushion: Diagonally forward leaning (PRT2).

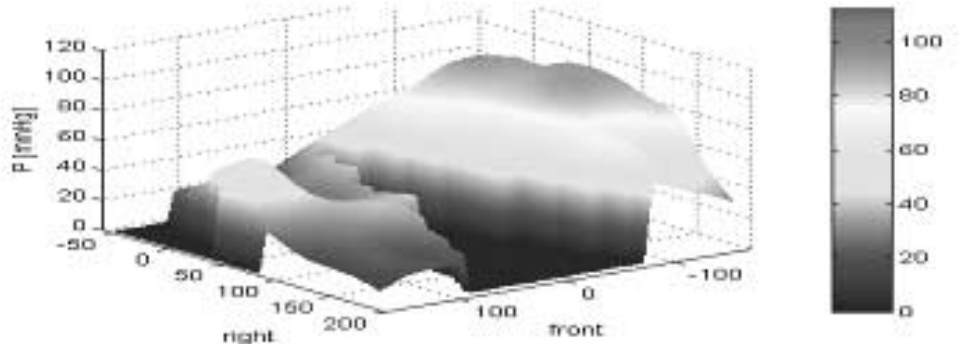

Figure 10: Dry Flotation Air cushion: Neutral sitting.

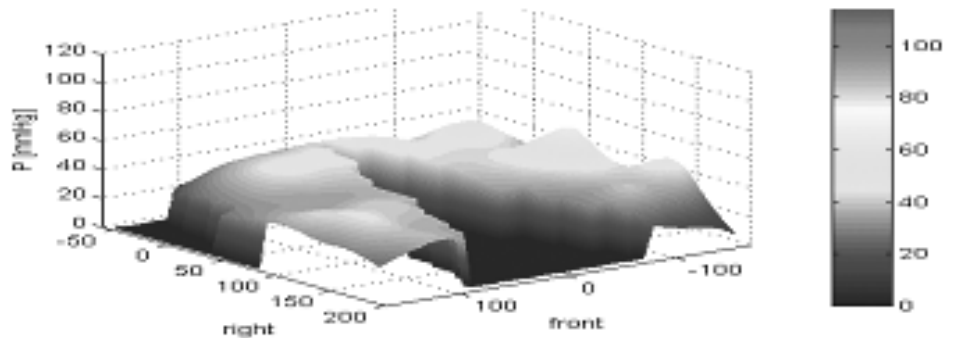

Figure 11: Dry Flotation Air cushion: Forward leaning (PRT1).

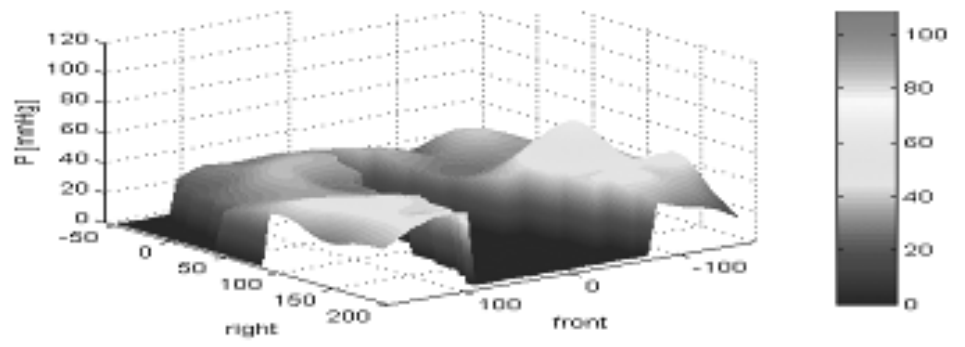

Figure 12: Dry Flotation Air cushion: Diagonally Forward leaning (PRT2).

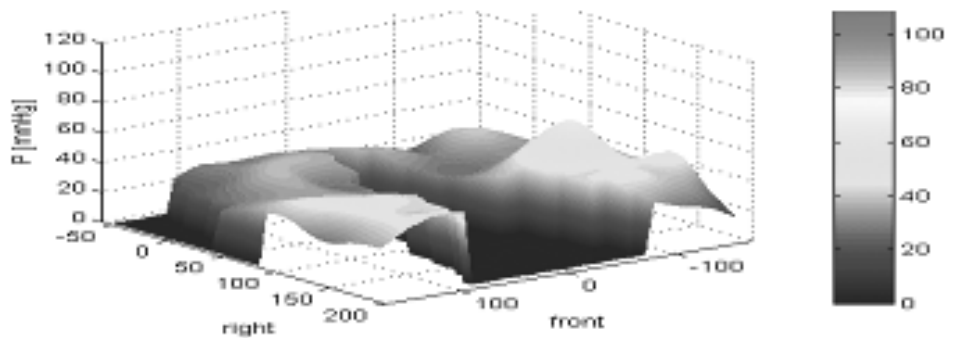

\section{REFERENCES:}

Bogie KM, Nuseibeh I, Bader DL. 1992 Transcutaneous gas tensions in the sacrum during the acute phase of spinal cord injury. English Medicine 206:1-6

Bromley I. 1998 Tetraplegia and Paraplegia. 5th edition. Churchill Livingstone, Edinburgh, p49 Exton-Smith AN, Sherwin RW. 1961 Prevention of pressure sores: Significance of spontaneous bodily movements. Lancet 11:1123-1126

Garber SL, Krouskop TA, Carter RE. 1978 A system for clinically evaluating wheelchair pressure relief cushions. American Journal of Occupational Therapy 32:565-570

Henderson JL, Price SH, Brandstater ME, Mondac BR. 1994 Efficacy of Three Measures to Relieve Pressure in Seated Persons with Spinal Cord Injury. Archives of Physical Medical Rehabilitation 75: 535-539

Kernozek TW, Lewin JE. 1998 Seat interface pressures of individuals with paraplegia: Influence of dynamic wheelchair locomotion compared with static seated measurements. Archives of Physical Medical Rehabilitation 79:313-315

Kosiak M. 1961 Etiology of decubitis ulcers. Archives of Physical medical Rehabilitation 42:19-29

Levine JM, Simpson M, McDonald RT. 1989 Pressure sores: A plan for primary care prevention. Geriatrics 44: 75-90

Muslumanoglu L, Aki S, Ozturk Y, Soy D, Filiz M, Karan A, Berker E. 1997 Motor, Sensory and Functional Recovery in Patients With Spinal Cord Lesions. Spinal Cord 35: 386 - 389

Phillips L, Ozer MN, Axelson P, Chizack H. 1987 Spinal Cord Injury. Raven Press, New York, p19, 124

Park CA. 1992 Activity Positioning and Ischial Tuberosity Pressure: A Pilot Study. The American Journal of Occupational Therapy 46: 904-909

Patterson RP, Fisher SV. 1980 Pressure and temperature patterns under the ischial tuberosities. Bull Prost Res 10:5-8

Reswick JB, Rogers JE. 1976 Experience at Rancho Los Amigos Hospital with devices and techniques to prevent pressure sores. In: Kenedi RM, Cowden JM, Scales JT (editors) Bedsore Biomechanics. Baltimore: University Park Press, 1976

Rosenthal MJ, Felton RM, Hileman DL, Lee M, Friedman M, Navach JH. 1996 A Wheelchair Cushion Designed to Redistribute Site of Sitting Pressure. Archives of Physical Medical Rehabilitation 77: 278-282

Salcido R, Carney J, Fisher S. 1993 A reliable animal model of pressure sore development: The role of free radicals. Journal of American Paraplegia Society 16:61

Somiya T, Kawamura K, Tokohiro A, Tackeki H, Ogata H. 1996 A Survey of Wheelchair Use by Paraplegic Individuals in Japan. Part One: Characteristics of Wheelchair Cushions. Spinal Cord 35: 590-594

Zacharow D. 1984 Wheelchair posture and pressure sores. Springfield II: Charles C Thomas 